\title{
KIWI: Building Innovative Knowledge Management Infrastructure within European Public Administration. The Case of Prefecture of Milan
}

\author{
Lara Gadda ${ }^{1}$, Emilio Bugli Innocenti ${ }^{2}$, and Alberto Savoldelli ${ }^{1}$ \\ ${ }^{1}$ Politecnico di Milano, 20133 Milano, Piazza Leonardo da Vinci 32, Italy \\ Tel. +39 02 23992796; Fax. +3902 23992720 \\ lara.gadda@polimi.it \\ ${ }^{2}$ Netxcalibur, 50123 Firenze, via Alamanni 25, Italy \\ Tel. +39055 285859; Fax. +39055285760 \\ ebi@acm.org
}

\begin{abstract}
The paper is composed by two parts. The first one is to show the main findings of the "as is" process analysis and "to be" process definition in the Prefecture of Milan, one of the users of KIWI project. This allows to present the improvement interventions in order to highlight the main user requirements for KIWI platform. It lets public employees access anywhere and anytime to relevant knowledge, transformed from implicit to explicit, through mobile devices. The second objective is to describe the development stage of KIWI platform that should be used to improve the efficiency and the effectiveness of public organisations. In particular, the project aims at developing innovative, user-relevant, wireless technologies which make the relationship between PA and citizens easier.
\end{abstract}

\section{Introduction}

In the last few years, industrialised Countries faced up the necessity of reforming Public Administration (PA), a crucial problem since that context is quickly evolving. The change in progress is moving along two directions: on one hand, the users require a Public Sector's "product" risen in value and, on the other hand, there's the need to provide better services using the same resources [1].

Public Sector reform started with the adoption of a new set of rules which led to the decentralisation and the modernisation [2], but the mere political rules' transformation is not enough and it is necessary to develop a specific method in order to enhance organisations' performance, efficacy and efficiency [3]. The technological innovation and web oriented technology are the necessary starting point for improving Public Administration performance. They need to be constantly accompanied by complementary changes in administrative and organisational fields. There is the necessity to use a "change management" which should combine with information technology, change of organisation and human resources management [4].

The dynamic environment, where Public Administration operates, requires the need to access information regardless of distance and language, paving the way to make mobile public services affordably and securely available by anyone, anytime and anyplace.

In this context KIWI project, a shared-cost RTD within Information Society Technologies (IST) programme, aims at developing innovative knowledge

The original version of this chapter was revised: The copyright line was incorrect. This has been corrected. The Erratum to this chapter is available at DOI: 10.1007/978-3-540-44836-5_33

M.A. Wimmer (Ed.): KMGov 2003, LNAI 2645, pp. 285-296, 2003.

(C) Springer-Verlag Berlin Heidelberg 2003 
management $(\mathrm{KM})$ infrastructures able to transform public administrations at any level inside Europe into knowledge driven and dynamically adaptive learning organisations and empower public employees to be fully knowledge workers.

The choice of focusing attention on KM arises from the fact that the Knowledge is more and more becoming the most valuable asset within an administration and KM is the key to the administration reaching its potential. Each government aims at making information easily accessible to everyone, including citizens, suppliers and partners, and converting that information into knowledge. Knowledge management can provide benefits to an administration's employee. Sharing and reusing intellectual capital increases effectiveness, productivity, and quality in many ways. The KM infrastructures are a support to remote workforce: it's essential to help public employees to access important information when they need to make decisions avoiding mistakes and learn from other employees' experience. Indeed, they provide efficient and time-saving solutions: leveraging the knowledge gained from experience enables a better workload distribution within organisations adding value to citizens' services.

The innovation of KIWI project consists of transforming relevant PA services in anywhere and anytime ones, leveraging the PA intellectual capital in their relevant processes, embedding knowledge management in the PA relevant processes and using mobile technology as enabler for managing knowledge in the PA relevant processes. In order to achieve its objectives, the project starts analysing the user requirements of the three Public Administrations involved in it: Prefecture of Milan in Italy, Gironde Department in France and Turku Local Authorities in Finland. This article focuses its attention on the case of the Prefecture of Milan.

\section{The Case of the PREFECTURE of MILAN}

The Prefecture of Milan is one of the 103 Italian Prefectures based in Italy depending by the Ministry of the Interior. The Prefectures are the natural liaisons between the central headquarter of the Ministry based in Rome and the local branches of the Interior Administration.

The Prefecture is a local body of the state Administration in charge of general affairs and government representative at provincial level. The chief of the Prefecture is the Prefect who is in charge of the role of mediator with the local Authorities in order to be able to solve citizens' problems. Therefore, the Prefect:

- represents the government at provincial level;

- carries on all functions of a local state administration not conferred on other Offices;

- supervises to the remaining administrative functions carried on by the State, in order to co-ordinate them those carried on by the Local Bodies, directly or through the presidency of the permanent Conference of the officers of the state Offices;

- keeps an eye on the administrative Authorities which operate in the province and replaces them, in case of urgent necessity, adopting the appropriate measures.

With regard to KIWI project, it's important to underline that the Ministry of the Interior and subsequently each Prefecture is especially interested in making its employees professionals knowledge workers and gaining more efficiency. Already equipped with laptops and mobile phones, the public employees are a highly mobile workforce with high information and communication needs. 
Indeed, employees need to communicate each other country-wide, need to exchange data, documents and opinions with other Government administrations at local (municipalities, health care centres, chamber of commerce, police, etc.), regional and national level (pension system bodies, etc). The main benefits from a wellstructures knowledge management process will be:

- faster and better informed decision making;

- improved customer service;

- returns on investment as productivity increases;

- innovation further stimulated by capitalising on knowledge and expertise;

- reductions in customer and staff frustration savings in time and effort;

- reductions in costs.

Today, the added value of a Public Administration doesn't consist in the realisation of a series of standard products, administrative acts, but rather in the orientation towards the citizen-user and, therefore, in the creation and integration of services which answer to real needs (multifunctional desks, call centres, etc.), in the capability of feeling and interpreting the signals and needs of the environment and in developing on real time innovative solutions by an interactive way. The allocation of the services implies a direct relationship with the citizens-users who are interested to the satisfaction of specific areas of needs.

An undifferentiated manpower, dedicated to routine activities, is not useful; the new Public Administration needs a lower and qualified number of people who are able to provide competence, initiative, know-how and co-operation and innovation ability, referred either to the use of technologies and to the process management or to care of interpersonal relationships. The human resource is the critical one. The capability to innovate and increase the quality and reduce costs and answer times depends not only on material, financial and technological investments, but also on the immaterial ones: on the people, on their training, on the relationship system and on the organisation culture.

\section{Presentation of the "As-Is" Analysis}

The Prefecture of Milan could be divided in five sectors: Cabinet Office, sector I, sector II, sector III, the decriminalisation. Each sector is characterised by several activities. KIWI project focuses its attention on the crucial ones as identified in table 1. The choice of the core activities has been done on the basis of the following elements:

- volume of work: this means the activity is relevant for the sector;

- presence of less standardised format: this means the realisation of a Knowledge Management System can help the employees in their work;

- interaction with Bodies which are external to the PAs involved in the project: this means there is the possibility to interact through the mobile devices.

It is possible to identify six classes of knowledge that result indispensable for PREFECTURE activities. The matrix, reported in table 2, shows the correspondences between knowledge and activities. This is just an indicative representation, because generally the activities are not completely separate and also various knowledge present some overlapping areas. 
Table 1. The core activities in PREFECTURE of Milan

\begin{tabular}{|c|c|c|c|c|c|c|c|c|c|c|c|}
\hline & \multicolumn{10}{|c|}{ ACTIVITIES } \\
\hline & & $\begin{array}{l}\bar{D} \\
.0 \\
0 \\
.00 \\
0 \\
0 \\
0\end{array}$ & 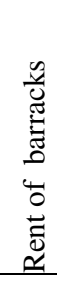 & 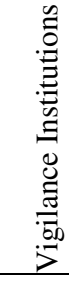 & 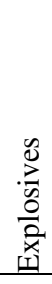 & 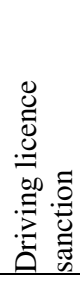 & 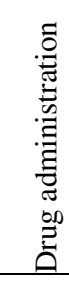 & 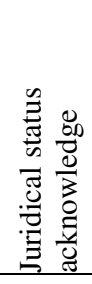 & 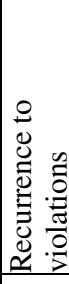 & 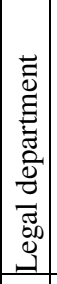 & 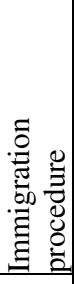 \\
\hline \multirow{5}{*}{ 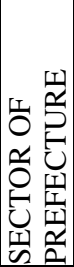 } & Cabinet Office & $\checkmark$ & & & & & & & & & \\
\hline & Sector I & & $\checkmark$ & $\checkmark$ & $\checkmark$ & & & & & & \\
\hline & Sector II & & & & & $\checkmark$ & $\checkmark$ & $\checkmark$ & & & \\
\hline & Decriminalisation & & & & & & & & $\checkmark$ & $\checkmark$ & \\
\hline & New activity & & & & & & & & & & $\checkmark$ \\
\hline
\end{tabular}

The operative rules are, for their own objectives, explicit and easily transferable. This knowledge is structured, almost fix, and can be easily communicate to employees. These rules are fix in the sense that they are rarely changed, because once a procedure is accepted it normally passes quite long time before to modify it.

The distinction between operative rules and Best Practices is very weak, in general it can be said that Best Practices become directly from the experience on particular problems, so they are generally less structured and verified, and they need some common background and/or context explanation to be properly understood. Moreover, this knowledge is continuously developing, depending on the actual needs and activities of various sectors.

The basic information and the in-depth knowledge of laws and rules required are other two examples of explicit, mainly fix, and easily transferable knowledge. Currently, various sectors have already arrange manuals and reference documents to collect this information and support the training and the daily activity of each activity.

The historical data are a whole of data and information that are used for various activities. In general, these are explicit and well structured information, so they are easily storable and transferable, even if these data are continuously developing and increasing.

The experience is the most difficult to manage because of its complexity. In fact, it is a whole of information that help the employees (usually at high level) to take the best decision on line with the context. In general, these are tacit and not well structured information, so they are hardly storable and transferable, also because these data are continuously developing and increasing.

Finally, legal competencies are often maintained at an informal level, even when it could be explicated, because it requires a certain effort to formalise and explicate it. Moreover, it's a developing knowledge, continuously increased and enriched by new experiences, new studies, or new situation. This requires an additional effort for maintaining information and knowledge constantly updated, otherwise it would lose its usefulness. At the same time, these competencies are quite difficult to 
communicate and transfer, because they need a specific and professional background to be understood.

Table 2. The Knowledge-Activities matrix in PREFECTURE of Milan

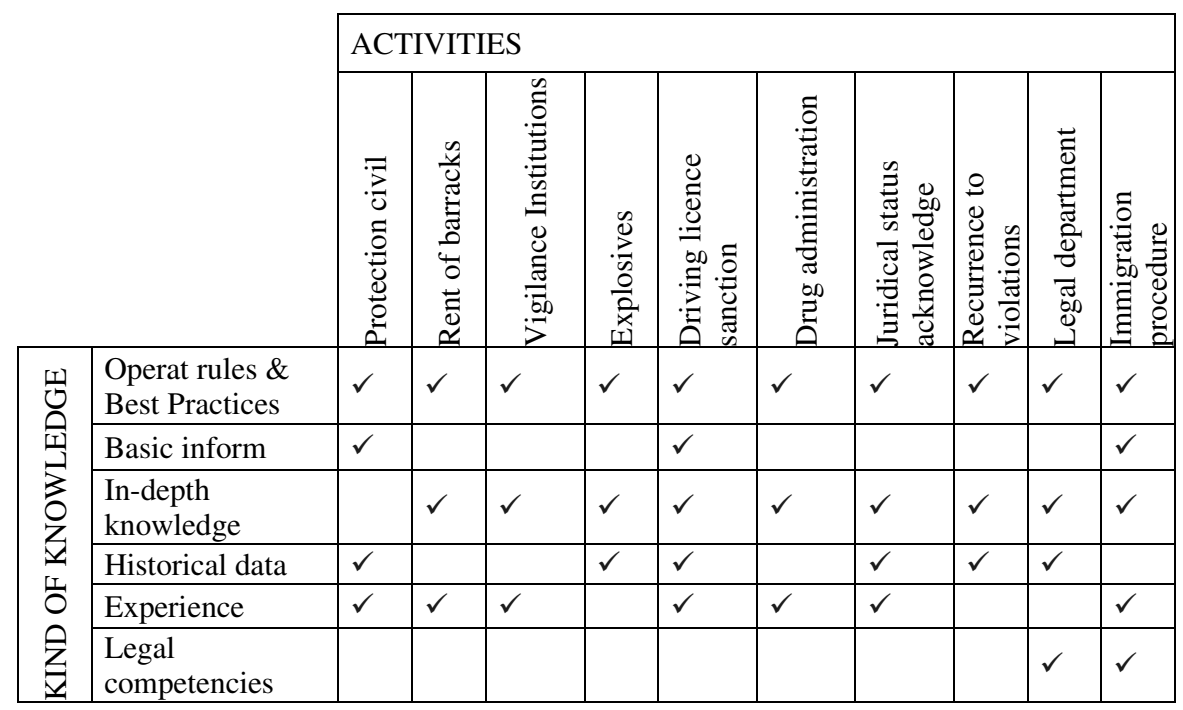

A first aspect to be underlined is the frequent use of informal methods to diffuse and share knowledge. Inside each sector, people have regular reunions and meetings, plus the possibility to co-operate for particular activities and to ask experts for any doubt. All these activities are positive and necessary, especially for creating a common vision and behaviour inside the sector, for strengthening relations and for motivation purposes, but they are not the most efficient solutions to diffuse explicit knowledge.

Training courses are not obligatory. In this case each sector is autonomous, but it's generally difficult to organise these courses because of the public expenditures and permits. Consequently sectors can't organise a course for any new employee. The most common solution is to collect relevant information in papery manuals and documents that are given to the new employees, then the core part of the training is "on the job" and new employees learn from the most experienced ones. Concerning manuals and documents, it's important to note that generally each sector has its own material that is not shared with other sectors. The consequence of this behaviour is the lack of uniformity among sectors and the duplication of many activities, since each sector dedicates time to prepare its own documents.

The table 3 resumes the outcomes of the "as-is" analysis of Knowledge Management process using the approach of the SWOT (Strengths, Weaknesses, Opportunities, and Threats) analysis. This allows to highlight the strength and weakness points of the organisation concerning Knowledge Management, but also to underline the opportunities that could be exploited and the threats that should be faced in introducing KIWI platform and new managerial approaches. 
Table 3. Knowledge Management SWOT analysis in PREFECTURE of Milan

\begin{tabular}{|c|c|}
\hline Strength points and Opportunities & Weakness points and Threats \\
\hline $\begin{array}{l}\text { PREFECTURE is quite used to } \\
\text { collect and store data and information }\end{array}$ & $\begin{array}{l}\text { Explicable knowledge is often maintained in } \\
\text { implicit form }\end{array}$ \\
\hline $\begin{array}{l}\text { The most part of relevant } \\
\text { data/knowledge can be easily } \\
\text { explicated and formalised }\end{array}$ & $\begin{array}{l}\text { Knowledge is not shared among the } \\
\text { organisation }\end{array}$ \\
\hline $\begin{array}{l}\text { PREFECTURE generates useful and } \\
\text { value-added knowledge }\end{array}$ & $\begin{array}{l}\text { Internal communication is quite poor and } \\
\text { the sectors are not used to co-operate }\end{array}$ \\
\hline $\begin{array}{l}\text { The PREFECTURE offices } \\
\text { collaborate with many external } \\
\text { bodies. Therefore, there is the } \\
\text { opportunity to share the knowledge } \\
\text { and information through mobile } \\
\text { devices }\end{array}$ & $\begin{array}{l}\text { Training activities are mainly informal with } \\
\text { loss of effectiveness }\end{array}$ \\
\hline & $\begin{array}{l}\text { IT tools are little diffuse inside } \\
\text { PREFECTURE and currently used tools are } \\
\text { little suitable for supporting knowledge } \\
\text { diffusion }\end{array}$ \\
\hline & $\begin{array}{l}\text { A lot of knowledge/documents are in papery } \\
\text { format }\end{array}$ \\
\hline
\end{tabular}

\section{Presentation of the "To-Be" Process}

The objectives of the improvement intervention on Knowledge Management in PREFECTURE could be resumed in five major points:

- to increase the efficiency of the knowledge management process, eliminating duplicate and inefficient activities;

- to increase the usefulness and the effectiveness of existent knowledge, improving its diffusion and usage;

- to favour the communication and the sharing of knowledge among different public bodies, facilitating the co-operation;

- to increase the uniformity among sectors, introducing common methods of work to ensure high quality services;

- to facilitate the organisation of training courses and improve their effectiveness.

Various instruments and interventions are necessary to reach these objectives, also because each typology of knowledge requires proper solutions. In general, it's possible to identify four major kind of interventions:

- a standardisation intervention, aimed at increasing the formalisation of information facilitating the processes of explication, collection, storing and diffusion of knowledge;

- the definition of rules and procedures common to all sectors, in order to increase the uniformity of action, obtain a common quality level, and facilitate co-operation and co-ordination among bodies; 
- the introduction of proper electronic databases for collecting, storing, and sharing information in an effective and efficient way. These "repositories of knowledge" should be useful also for training the new employees;

- the introduction of the use of the new mobile devices and methods of work aimed at increasing and supporting information sharing and co-operation among bodies.

More specifically, the standardisation intervention is the first step for the introduction of proper electronic databases. At this moment, some sectors have already developed their own database that generally are simple Excel or Access databases made by employees. The possibilities of these systems are quite limited and, most of all, they are not shared among other sectors and public bodies. What KIWI plans to do is the introduction of proper Knowledge Warehousing system that allows to store various kind of knowledge, to make queries, researches and statistical analysis on stored data, and to share them inside the whole Public Administration.

Analysing the specific reality of PREFECTURE, the standardisation process appears to be necessary mainly for operative rules, together with the definition of common and shared rules for all bodies involves in a specific activity to increase the uniformity of action and quality, basic information, in-depth knowledge and historical data. The output will be a series of databases and common procedures that could be used for the daily activities, for the training courses, for making specific researches and analyses, and for substituting current reference manuals that are different for each sector.

On the whole, this intervention will increase the uniformity among sectors and public bodies facilitating co-ordination and co-operation, but will also improve the overall efficiency through the elimination of duplicated activities and a more effective access to information. In addition, the proposed system shall permit the realisation of statistical analysis and researches, especially, but not only, for the historical data. This will add further value to the data stored in the database, increasing the advantage of their use.

Concerning experience and Best Practices, it has been already told that this is a more complex and partially not explicable knowledge. In this case the improvement intervention aims at developing adequate databases to collect this know-how and proper methods of work for increasing their diffusion inside the whole Public Administration.

The databases for this kind of knowledge haven't to be too rigid, even if a minimum of structure is necessary for effectively retrieving stored information. The better solution will be probably the definition of electronic databases where to insert various kind of documents, that will be mainly texts, but also images. Afterward, a full text research system is necessary, for effectively retrieving information among stored documents independently from their structure. This solution facilitates the use of the database, because it doesn't bind the possibilities of data insertion and, at the same time, ensures a good effectiveness for the research phase.

Nevertheless, a database can store only those knowledge and information that can be explicate and described in a written document, however correlated by images or photos. For those know-how that can't be completely explicated because is too related to specific competencies or to the context, the better solution is to provide a list of "internal experts" and proper mobile tools for supporting direct communication, as internal e-mail, electronic forums, or systems for video-conferencing. This systems allow people to directly discuss various cases and situations, sharing those part of 
knowledge that can't be put in a database. Obviously, this system is useful and valuable not inside the single sector, where people can directly meet and co-operate, but most of all among various public bodies, to increase knowledge diffusion and sharing inside the whole organisation, with the final result to increase its overall knowledge and the quality of services.

\subsection{The Improvement Plan}

Once the possible interventions for improving the Knowledge Management process inside PREFECTURE has been defined, it's necessary to translate these ideas and suggestions in operative plans that shall be then implemented.

Due to the specificity to the public sector, it could be preferable to limit the breadth of the interventions in order to easily manage it and increase the probability of a success. At the same time, it's important to produce real and tangible results for the considered organisation, and this is not possible with a too small field of intervention. In the case of PREFECTURE the better solution seems to be to concentrate the attention on one of the main activities, the immigration procedure.

This solution allows to analyse different kind of knowledge and includes all the typologies of intervention described above (actually, the knowledge of the historical data is not indicated, but only because the activity is a new one for the Prefecture. In the future also the knowledge of the historical data will be essential). On the same time, concentrating the effort on a specific activity, the analysis and intervention phases are simpler and the final results will be more tangible and verifiable. The table 4 reports the reasons for choosing this field of intervention and the expected results for it:

Table 4. Reasons and objectives of the fields of intervention

\begin{tabular}{|c|c|c|}
\hline & Reason of the chose & Objectives of the intervention \\
\hline 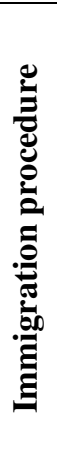 & $\begin{array}{l}\text { It represent } s \text { an innovative } \\
\text { process since it is a new } \\
\text { activity also for the } \\
\text { Prefecture; } \\
\text { It involves different kind of } \\
\text { people characterised by } \\
\text { different knowledge. Each } \\
\text { of them is in charge of a } \\
\text { part of the whole procedure; } \\
\text { It offers the opportunity to } \\
\text { use the mobile technologies }\end{array}$ & $\begin{array}{l}\checkmark \text { To increase the efficient and the } \\
\text { effectiveness of the service; } \\
\checkmark \text { To obtain uniform and high } \\
\text { standards of quality; } \\
\checkmark \text { To ensure an high level of users } \\
\text { satisfaction }\end{array}$ \\
\hline
\end{tabular}

\subsection{User Requirements for KIWI Platform}

It is now possible to define the User Requirements of PREFECTURE of Milan for the KIWI platform as indicated in table 5: 
Table 5. User Requirements of Prefecture of Milan for KIWI Plat

\begin{tabular}{|c|c|c|}
\hline Relevant characteristics & Intervention Objectives & User Requirements \\
\hline $\begin{array}{l}\text { Great information and } \\
\text { knowledge: procedure by } \\
\text { procedure, the experience } \\
\text { grows up and it' essential } \\
\text { to allow its transfer to all } \\
\text { employees }\end{array}$ & $\begin{array}{l}\text { - Help remote workforce to } \\
\text { access important } \\
\text { information when they need } \\
\text { to make decisions avoiding } \\
\text { mistakes and learn from } \\
\text { other employees' } \\
\text { experience }\end{array}$ & $\begin{array}{l}\text { - Support to remote } \\
\text { workforce }\end{array}$ \\
\hline $\begin{array}{l}\text { Wrong workload distribu- } \\
\text { tion within organisation; no } \\
\text { addition of value to client } \\
\text { (citizens, businesses) service }\end{array}$ & $\begin{array}{l}\text { - Increase the efficiency, } \\
\text { reducing duplicated } \\
\text { activities, sharing best } \\
\text { practices, automating some } \\
\text { repetitive or easy activities, } \\
\text { introducing IT tools }\end{array}$ & $\begin{array}{l}\text { - Efficient and time- } \\
\text { saving solutions }\end{array}$ \\
\hline $\begin{array}{l}\text { Difficult communications } \\
\text { and information exchange } \\
\text { among Public Bodies }\end{array}$ & $\begin{array}{l}\text { - Increase the sharing of data } \\
\text { and information inside and } \\
\text { among the Public Bodies; } \\
\text { - Facilitate the internal } \\
\text { communication }\end{array}$ & $\begin{array}{l}\text { - Support asynchronous } \\
\text { and long distance } \\
\text { communications; } \\
\text { - Provide a safe, } \\
\text { common environment } \\
\text { where to share } \\
\text { documents }\end{array}$ \\
\hline $\begin{array}{l}\text { Tendency to maintain the } \\
\text { knowledge implicit }\end{array}$ & $\begin{array}{l}\text { - Facilitate the formalisation, } \\
\text { the storing, and the } \\
\text { diffusion of the know-how }\end{array}$ & $\begin{array}{l}\text { - } \begin{array}{l}\text { Introduce of proper } \\
\text { databases } \\
\text { document } \\
\text { management systems; }\end{array} \\
\text { - } \begin{array}{l}\text { Manage both } \\
\text { structured and non- }\end{array} \\
\text { structured data; } \\
\text { - Use of a full text } \\
\text { research system for } \\
\text { retrieving information }\end{array}$ \\
\hline $\begin{array}{l}\text { Difficulty in organising the } \\
\text { training courses for the new } \\
\text { employees }\end{array}$ & $\begin{array}{l}\text { - Use the stored know-how } \\
\text { and the communication } \\
\text { facilities for improving the } \\
\text { training courses }\end{array}$ & $\begin{array}{l}\text { - Definition and use of } \\
\text { standard training } \\
\text { modules with proper } \\
\text { support } \\
\text { documentation } \\
\end{array}$ \\
\hline $\begin{array}{l}\text { Difficulties in measuring } \\
\text { organisational } \\
\text { performances and citizens } \\
\text { satisfaction }\end{array}$ & $\begin{array}{l}\text { - Introduce instruments and } \\
\text { methodologies for } \\
\text { measuring the performance } \\
\text { of the organisation and } \\
\text { citizens/supporter } \\
\text { satisfaction }\end{array}$ & 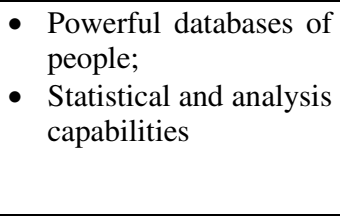 \\
\hline Low familiarity with IT tools & $\begin{array}{l}\text { - Increase the usability and } \\
\text { easiness of the proposed } \\
\text { solution }\end{array}$ & 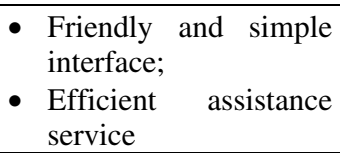 \\
\hline
\end{tabular}




\section{KIWI System Architecture}

The KIWI platform will be structured around the following items:

- A web-based Intranet Knowledge Warehousing Toolset that will allow to build a wirelessly accessible knowledge warehouse. The knowledge warehousing will amass internal and external knowledge;

- A Mobile Collaborative Environment to support a realistic collaboration and knowledge sharing and transferring also among geographically distributed workforces, within and between public administrations. It will represent the convergence of technologies such as multimedia document/image management, videoconferencing, and mobile $3 \mathrm{G}$ technologies helping public administrations transcend all sorts of boundaries by making available the right information to the right employee at the right place and at the right time.

\subsection{The Components}

The KIWI platform is based on a Intranet Knowledge Warehousing Toolset. These tools will allow to build a wirelessly accessible knowledge warehouse (knowledge resources will includes manuals, letters, responses from citizens/companies, news, technological, organisational, legal and other relevant information from administrations, as well as knowledge derived from work processes) applications that support inter-organisational learning process.

At the hearth of the system lies the information hierarchy which acts as the conceptual/semantic glue linking our Knowledge Warehouse. Surrounding this core, the XHTML, the new XML-based W3C/WAP standard for wireline and wireless information and Java agents technologies will stand.

The final layer of this processing layer will contain the needed tools to support Knowledge Warehousing activities, and namely, the Browsing, Query (support ad-hoc queries, reporting and analysing information, which will rely on existing OnLine Analytical Processing systems) the Smart Profiling, and the Suggesting Engine.

The KIWI Knowledge Warehouse will be set to deliver the right information to the right employee at the right place and at the right time.

The Browsing Tool will allow for locating and accessing information throughout the Knowledge Warehouse. Client applications consulting catalogues will access both information and meta-information so as to achieve a full multimedia (including video, audio, image, text, web pages, CAD \& GIS, etc.) Knowledge Warehousing functionality.

The KIWI Smart Profiling Engine will drive any specific content from employee records and interests. KIWI will combine rule-based (ie, using pre-specified rules to take action), collaborative filtering (ie, by automatically comparing attributes of one set of employee data with other employees, suggesting ideas for personalisation).

The KIWI Suggesting Engine will analyse each employee's feedback and generates their profile, which it refines further and further. It will use its learning to recommend information items appropriate to each employee's record, tastes and preferences.

The second Tool which composes the KIWI platform is the KIWI Mobile Collaborative Environment. The Groupware can help Public Administrations 
transcend all sorts of boundaries. Geography, time and organisational structure fade in importance in the groupware-enabled process.

At the same time, mobile technologies are increasingly penetrating businesses, offering anytime/anyplace access to enterprise information. The novelty of the KIWI approach lies in the convergence of these two technologies.

The challenge of Mobile Groupware Tool development within KIWI is twofold:

- firstly, to allow for web-based, mobile groupware by supporting both synchronous (ie, real-time interaction such videoconferencing, chatting, electronic whiteboard, etc.) and asynchronous (ie, email, group discussions, etc.) communication, including live video/audio/text communications. The foreseen work will be centred around the metaphor of a mobile sharable desktop, storing artefacts that are related to projects, such as documents and reports and organising communication between group and team members through the organisation of email, messaging and calendar management. Additionally, automated wireless workflows on-the-fly set up will be also crucial not only to automate repetitive tasks but also to tracking and incorporating employee comments and feedback within the process;

- secondly, to take full advantage of the Knowledge Warehousing tools, by integrating mobile groupware facilities within the KIWI Toolset. This will lead to set up of a full Mobile Collaborative Environment.

The project will look at the recent advancements in the mobile groupware standardisation such as the GroupDX initiative, proposing an industrial grade XML Document Type Definitions (DTDs) and Object Schemata for Internet groupware applications. This new standard, called Groupware Mark-up Language (GML), is being established in order to facilitate data exchange among the various groupware applications, and facilitate data synchronisation among groupware applications and their individual counterparts.

\section{Conclusions}

The KM will result into a decisive improvement in inserting an information database. This allows the public employees to access easier to the needed data, independently from the place where they are.

Concerning the exploitation of project outcomes for the industrial component of the Consortium, this will mainly result in the commercialisation of the prototypes produced within the project. Indeed, all prototypes will be used as basic elements to develop and produce marketable results: as in-house developments by each partner and in collaboration with project partners. A quick process of research transfer in production will assure to the Consortium partners an essential competitive advantage for a further consolidation of the respective positions on the market. Moreover, the specific techniques implemented in the project will be used by most of the Partners to enhance the techniques already in use, contributing to consolidate a competitive advantage.

Once the innovative technologies are implemented, the idea is to realise a mobile groupware which let in-house functions be used at distance. It involves an organisation and a management changes between headquarter and branches. 
Within this structure, the willingness of the Public Authorities involved in the project to provide a common exploitation of the project results, constitutes the cornerstone of the KIWI Exploitation Strategy.

\section{References}

[1] AIPA, "La reingegnerizzazione dei processi nella pubblica amministrazione", (1999)

[2] Klages, H., Loffler, E., "Administrative modernisation in Germany - a big qualitative jump in small steps", International Review of Administrative Sciences, pp. 373-384, (1995)

[3] Hammer, M., Champy, J., "Reengineering The Corporation: A Manifesto for Business Revolution", HarperCollins, New York, (1993)

[4] Osborne, D., Gaebler, T., "Reinventing Government. How the entrepreneurial spirit is transforming the public sector", New York, Plume, (1993) 